\title{
UM MAPEAMENTO DE PESQUISAS SOBRE O USO DE MATERIAIS CURRICULARES EDUCATIVOS NA FORMAÇÃO DE PROFESSORES DE MATEMÁTICA
}

\author{
Darling Domingos Arquieres* \\ Marcelo Almeida Bairral ${ }^{* *}$
}

\section{Resumo}

O presente artigo apresenta um levantamento bibliográfico de pesquisas pautadas no uso de Materiais Curriculares Educativos (MCE) como proposta de desenvolvimento profissional de professores de matemática ${ }^{1}$. Os MCE são recursos preparados para apoiar professores, particularmente, por possuírem informações que possibilitam uma noção de como estruturar aulas ou novas práticas pedagógicas. Neste levantamento, foram detectados 18 artigos em nove periódicos de Educação Matemática. É possível verificar que os MCE ainda são incipientes na pesquisa brasileira em Educação Matemática com docentes. O texto traz contribuições para a conceituação desse tipo de recurso e sintetiza como as pesquisas mapeadas estão utilizando esses materiais formativos.

Palavras-chave: Educação Matemática. Materiais Curriculares Educativos. Desenvolvimento profissional docente. Formação continuada em Matemática. Educação básica.

\section{INTRODUÇÃo}

Pesquisadores têm desenvolvido Materiais Curriculares Educativos (MCE) com intenção de apoiar professores na execução de novas práticas pedagógicas (OLIVEIRA; BARBOSA, 2014; REMILLARD; HERBELEISENMANN; LLOYD, 2009). Alguns desses MCE estão disponíveis em ambientes virtuais e, dessa forma, ampliam a acessibilidade e a socialização de práticas (BAIRRAL, 2016). Esses recursos formativos disponíveis na rede são denominados Materiais Curriculares Educativos Online (MCEO).

Este artigo integra uma pesquisa de mestrado em Educação em Ciências e Matemática² ${ }^{2}$ que tem sua centralidade no uso de MCEO na formação continuada de professores. O objetivo do artigo é apresentar um mapeamento de pesquisa $^{3}$ (FIORENTINI; PASSOS; LIMA, 2016) realizado em nove periódicos que publicam pesquisas em educação matemática. Foram capturados estudos focados no uso de Materiais Curriculares (MC) para o desenvolvimento profissional docente. Os focos específicos do mapeamento são: (1) identificar a abordagem conceitual de MC adotada (ou explicitada) em cada estudo e (2) identificar investigaçóes que visam ao uso de Materiais Curriculares Educativos na aprendizagem do professor.

Mestranda do Programa de Pós-Graduação em Educação em Ciências e Matemática (PPGEduCIMAT) da Universidade Federal Rural do Rio de Janeiro (UFRRJ). Professora da Secretaria de Estado de Educação do Rio de Janeiro (SEEDUC/RJ). E-mail: reidarling@gmail.com

Doutor em Educação Matemática. Professor do Programa de Pós-Graduação em Educação em Ciências e Matemática (PPGEduCIMAT) da Universidade Federal Rural do Rio de Janeiro (UFRRJ). E-mail: mbairral@ufrrj.br 


\section{Busca preliminar e organização DO MATERIAL BRUTO}

Este levantamento foi feito a partir de artigos disponíveis em algumas das principais revistas ${ }^{4}$ eletrônicas em Educação Matemática, a saber: JIEEM, Educação Matemática Pesquisa, BOLEMA, Boletim GEPEM online, ACTA SCIENTIAE, Educação Matemática em Revista, Zetetiké, Perspectivas da Educação Matemática e REVEMAT.
A busca foi desenvolvida em três camadas, a saber: 1a) a palavra-chave Materiais Curriculares; $2^{a}$ ) observaçóes que indiquem a ligação entre MCE e professor(es), fazendo referência a práticas pedagógicas ou ao desenvolvimento profissional docente; $3^{\mathrm{a}}$ ) a metodologia que apresente a implementação dos MCE por professores.

A busca inicial contemplou trabalhos compreendidos no período entre $2011^{5}$ e 2017. O Quadro 1 ilustra o quantitativo dos trabalhos capturados com a palavra-chave Materiais Curriculares.

\begin{tabular}{|c|c|}
\hline \multicolumn{1}{|c|}{ REVISTA } & NÚMERO DE TRABALHOS \\
\hline JIEEM & 1 \\
\hline Educação Matemática Pesquisa & 4 \\
\hline BOLEMA & 2 \\
\hline GEPEM & 2 \\
\hline Acta Scientiae & 1 \\
\hline Educação Matemática em Revista & 3 \\
\hline Zetetiké & 2 \\
\hline Perspectivas da Educação Matemática & 2 \\
\hline REVEMAT & 1 \\
\hline Total de artigos & 18 \\
\hline
\end{tabular}

Quadro 1 - Organização de levantamento bibliográfico

Fonte: Elaboração própria

A partir dessa catalogação, revisitamos cada artigo com o propósito inicial de identificar os que faziam referência a MC e a MCE. Com isso, procuramos identificar se havia, nos estudos capturados, uma diferenciação conceitual entre esses dois tipos de recursos.

\section{Foco 1: EM BUSCA DE UMA CONCEITUAÇÃO}

Em cada um dos artigos encontrados na busca citada anteriormente, verificamos a referência de autores a MC, a saber: 


\begin{tabular}{|c|c|}
\hline AUTOR(ES)/ANO & MATERIAIS CURRICULARES: REFERÊNCIA DE AUTORES \\
\hline Aguiar e Oliveira, 2014 & $\begin{array}{c}\text { Materiais Curriculares são "[...]como um veículo fundamental para a inclusão de novas ideias sobre o } \\
\text { ensino e a aprendizagem de disciplinas escolares. Nesse sentido, citando Stein e Kim (2009), os autores } \\
\text { acrescentam que Materiais Curriculares podem desempenhar o papel de agente de mudança, no sentido de } \\
\text { facilitar mudanças na prática pedagógica" (p. 581). }\end{array}$ \\
\hline Aguiar e Oliveira, 2017 & $\begin{array}{l}\text { “[...] Materiais Curriculares reporta-se aos recursos didáticos que estão à disposição de professores no } \\
\text { sentido de utilizar para apoiar o ensino e a aprendizagem da matemática. Tais materiais podem ter a } \\
\text { função de mediadores na relaçáo professor-estudante-conteúdo disciplinar." (p. 405) }\end{array}$ \\
\hline $\begin{array}{l}\text { Crisostomo, Januário e } \\
\quad \text { Lima, } 2017\end{array}$ & $\begin{array}{l}\text { São recursos "para mediar/promover situações de aprendizagem matemática, os professores recorrem a } \\
\text { diferentes materiais disponibilizados pelos sistemas de ensino, públicos ou privados, como livros didáticos, } \\
\text { apostilas ou cadernos de atividades" (p. 63). }\end{array}$ \\
\hline $\begin{array}{l}\text { Januário, Lima e } \\
\text { Manrique, } 2017\end{array}$ & $\begin{array}{c}\text { Considera os Materiais Curriculares como ferramentas em que a relação entre materiais e professor são } \\
\text { "agentes ativos do desenvolvimento curricular, em que ambos trazem suas características e propriedades } \\
\text { para a interação entre si; os professores agem sobre os materiais, moldando-os, e os materiais agem sobre os } \\
\text { professores, moldando suas práticas pedagógicas" (p. 418). }\end{array}$ \\
\hline Lima e Borba, 2017 & $\begin{array}{l}\text { Referencia que "[...] a concepção de que Materiais Curriculares são uma representação fixa do currículo } \\
\text { engessa o desenvolvimento curricular" (JANUÁRIO; LIMA; PIRES, 2016, p. 4), pois o currículo, em } \\
\text { suas diferentes instâncias, também é influenciado, moldado e adaptado a partir do momento em que dele } \\
\text { é feito uso. [...] o uso do currículo envolve as interaçóes entre o professor e os materiais que apresentam } \\
\text { as orientaçôes curriculares, sejam elas referentes ao currículo prescrito ou ao currículo apresentado. Tais } \\
\text { materiais são denominados por Remillard (2005) como Materiais Curriculares" (p. 819-820). }\end{array}$ \\
\hline $\begin{array}{l}\text { Oliveira, Oliveira e Silva, } \\
\qquad 2017\end{array}$ & $\begin{array}{l}\text { "Os materiais impressos publicados para serem usados por professores que ensinam Matemática e } \\
\text { estudantes, como exemplo, listas de exercícios e tarefas matemáticas, são compreendidos também, neste } \\
\text { estudo, como Materiais Curriculares, sendo aqueles destinados a promover a aprendizagem de estudantes } \\
\text { (SHENEIDER; KRAJCIK, 2002; DAVIS; KRAJCIK, 2005; REMILLARD, 2005).” (p. 43) }\end{array}$ \\
\hline $\begin{array}{l}\text { Oliveira, Ribeiro e } \\
\text { Powell, } 2016\end{array}$ & Não há apresentação de definição. Há apenas referência no título, no resumo e nas palavras-chave. \\
\hline Pacheco e Pires, 2015 & $\begin{array}{l}\text { "De acordo com Brown (2009), [...] os Materiais Curriculares são artefatos, ou seja, instrumentos que } \\
\text { representam e transmitem modos de açáo, auxiliando o planejamento e a prática docente." (p. 238) }\end{array}$ \\
\hline Pires, 2016 & $\begin{array}{l}\text { “Usamos a expressão 'Materiais Curriculares' em referência ao conjunto de ferramentas disponibilizadas } \\
\text { aos professores para desenvolver o currículo de Matemática, quais sejam livros didáticos, materiais } \\
\text { apostilados ou cadernos elaborados por secretarias de educação (JANUÁRIO, 2015a).” (p. 47) }\end{array}$ \\
\hline $\begin{array}{l}\text { Prado, Oliveira e } \\
\text { Barbosa, } 2016\end{array}$ & $\begin{array}{l}\text { "Materiais Curriculares, tais como livros didáticos, planos de aula e tarefas para os estudantes, são } \\
\text { importantes recursos sobre os quais os professores se baseiam para organizar tanto o planejamento quanto } \\
\text { o ensino (BEN-PERETZ, 2009)." (p. 739) }\end{array}$ \\
\hline
\end{tabular}

Quadro 2 - Referência a Materiais Curriculares

Fonte: Elaboração própria

Diante das informaçóes registradas no Quadro 2, percebemos que Materiais Curriculares são considerados como ferramentas (JANUÁRIO; LIMA; MANRIQUE,
2017), artefatos (Brown, 2009 apud Pacheco; Pires, 2015) ou recursos didáticos (AGUIAR; OLIVEIRA, 2017). São exemplos: lista de exercícios, livros didáticos, planos de 
aulas, apostilas, cadernos de atividades etc. (Crisostomo; Januário; Lima, 2017). Esses materiais têm como propósito a aprendizagem dos estudantes (Oliveira; Oliveira; Silva, 2017), são considerados guias para que os professores desenvolvam o currículo de matemática (Lima; Borba, 2017; Pires, 2016) e são base para organização de seus planejamentos (Prado; Oliveira; Barbosa, 2016).

Os artigos do Quadro 3 fazem referência a MCE:

\begin{tabular}{|c|c|}
\hline AUTOR(ES)/ANO & MATERIAIS CURRICULARES EDUCATIVOS \\
\hline Aguiar e Oliveira, 2014 & $\begin{array}{l}\text { "Materiais Curriculares que são projetados para apoiar tanto a aprendizagem de estudantes quanto de } \\
\text { professores (DAVIS; KRAJCIK, 2005; EISENMANN; EVEN, 2009), [...] denominados Materiais } \\
\text { Curriculares Educativos. O fato de apresentar como objetivo promover aprendizagem de professores, } \\
\text { além da aprendizagem de estudantes, é o que distingue Materiais Curriculares Educativos de Materiais } \\
\text { Curriculares (BALL; COHEN, 1996; DAVIS; KRAJCIK, 2005)." (p. 581) }\end{array}$ \\
\hline Aguiar e Oliveira, 2017 & $\begin{array}{l}\text { "Remillard (2005) sinaliza que esses novos Materiais Curriculares foram projetados para serem educativos } \\
\text { para professores. Portanto, o objetivo de promover a aprendizagem de professores além da aprendizagem } \\
\text { de estudantes é o que distingue os Materiais Curriculares Educativos dos Materiais Curriculares (BALL; } \\
\text { COHEN, 1996; DAVIS; KRAJCIK, 2005)." (p. 407) }\end{array}$ \\
\hline Bairral, 2016 & $\begin{array}{l}\text { Caracteriza os Materiais Curriculares Educativos "como artefatos, Brown (2009) destaca seu potencial para } \\
\text { documentar e transmitir práticas, reforçar ideias e normas culturais e influenciar o ensino e os professores" } \\
\text { (p. 78). }\end{array}$ \\
\hline Boas e Barbosa, 2016a & $\begin{array}{l}\text { "Materiais didáticos, desenvolvidos para apoiar o professor, além de servir aos alunos na sala de aula, } \\
\text { podem ser denominados de Materiais Curriculares Educativos (MCE) (DAVIS; NELSON; BEYER, 2008; } \\
\text { SCHENEIDER; KRAJCIK, 2000)." (p. 145) }\end{array}$ \\
\hline Boas e Barbosa, 2016b & $\begin{array}{l}\text { "Materiais como estes, que são desenvolvidos visando, além da aprendizagem do aluno, promover também } \\
\text { a aprendizagem do professor, são denominados Materiais Curriculares Educativos (BALL; COHEN, 1996; } \\
\text { DAVIS; NELSON; BEYER, 2008)." (p. 92) }\end{array}$ \\
\hline Oliveira, 2016 & $\begin{array}{l}\text { “[...] é designada por Remillard (2005) como 'Materiais Curriculares Educativos', que são aqueles } \\
\text { produzidos para apoiar tanto a aprendizagem de estudantes quanto a de professores (DAVIS \& KRAJCIK, } \\
\text { 2005).” (p. 160) }\end{array}$ \\
\hline Oliveira e Barbosa, 2016 & $\begin{array}{l}\text { “A expressão 'Materiais Curriculares Educativos (MCE)’ refere-se a materiais desenvolvidos para apoiar } \\
\text { professores na implementação de propostas pedagógicas nos contextos escolares (REMILLARD; } \\
\text { HERBEL-EISENMANN; LLOYD, 2009; GUEUDET, PEPIN; TROUCHE, 2012).” (p. 117) }\end{array}$ \\
\hline Palanch, 2016 & $\begin{array}{l}\text { “A expressão 'Materiais Curriculares Educativos' caracteriza-se por promover tanto a aprendizagem de } \\
\text { estudantes quanto de professores (DAVID; KRAJCIK, 2005). Remillard et al. (2009) mostram que } \\
\text { escritores de materiais curriculares começaram a desenvolver Materiais Curriculares Educativos que } \\
\text { apoiam professores a imaginar diferentes formas de estruturar aulas da disciplina Matemática e de } \\
\text { interagir com estudantes, ou seja, materiais que são educativos para professores. Assim, materiais com essa } \\
\text { característica são denominados de Materiais Curriculares Educativos (BALL; COHEN, 1996; DAVID; } \\
\text { KRAJCIK, 2005).” (p. 1.061) }\end{array}$ \\
\hline $\begin{array}{c}\text { Prado, Oliveira e } \\
\text { Barbosa, } 2014\end{array}$ & $\begin{array}{l}\text { “[...] Davis e Krajcik (2005) têm apontado algumas heurísticas para o delineamento de Materiais } \\
\text { Curriculares, nas quais é enfatizada uma ligaçâo entre um conteúdo (o que pode ser ensinado) e uma } \\
\text { base coerente para abordagem instrucional (o como pode ser ensinado). Eles têm denominado Materiais } \\
\text { Curriculares com tal característica de Materiais Curriculares Educativos - MCE.” (p. 506) }\end{array}$ \\
\hline
\end{tabular}




\begin{tabular}{|c|c|}
\hline $\begin{array}{c}\text { Prado, Oliveira e } \\
\text { Barbosa, 2016 }\end{array}$ & $\begin{array}{c}\text { Materiais Curriculares “[...] elaborados com o fim de subsidiar as práticas pedagógicas escolares são } \\
\text { denominados Materiais Curriculares Educativos (MCE) (DAVIS; KRANJCIK, 2005)" (p. 739). }\end{array}$ \\
\hline $\begin{array}{c}\text { Silva, Barbosa e Oliveira, } \\
2012\end{array}$ & $\begin{array}{c}\text { Materiais Curriculares Educativos sendo apoio de aprendizagem tanto para o aluno como ao professor. } \\
\text { "Nessa perspectiva, os materiais devem apresentar elementos que apoiem, também, a aprendizagem do } \\
\text { professor; que o possibilite vislumbrar como pode ser desenvolvida determinada tarefa em sala de aula." } \\
\text { (p. 242) }\end{array}$ \\
\hline
\end{tabular}

Quadro 3 - Referência a Materiais Curriculares Educativos

Fonte: Elaboração própria

A análise das definiçóes apresentadas no Quadro 3 indica que MCE são projetados para apoiar tanto a aprendizagem de estudantes quanto a de professores (AGUIAR; OLIVEIRA, 2014; BOAS; BARBOSA, 2016b; OLIVEIRA, 2016; PALANCH, 2016), a fim de auxiliar os educadores na execução de propostas pedagógicas em contextos escolares (Oliveira; Barbosa, 2016).

Esses recursos, que relacionam $o$ que $e o$ como ensinar (PRADO; OLIVEIRA; BARBOSA, 2014), também documentam e transmitem práticas profissionais ocorridas (BAIRRAL, 2016) e apresentam aos professores meios para imaginar diferentes formas de estruturar aulas dos conteúdos matemáticos e de relacionar com os estudantes (PALANCH, 2016). Cabe lembrar que um MCE é um tipo de MC e a publicação online transforma um MCE em um MCEO.

Sintetizada a conceituação de MCE das investigaçóes (Quadro 3), a próxima análise focou nos artigos que fazem referência aos MCE como um tipo de recurso que tem a intençáo de possibilitar a aprendizagem do professor.

\section{Foco 2: Materiais Curriculares EDUCATIVOS E SUAS CONTRIBUIÇÓES}

A partir dos 11 artigos que constam no Quadro 3, que apresenta MCE voltado à aprendizagem docente, traçamos dois passos para seleção e análise: 1. Tópicos importantes; 2. Metodologia da pesquisa.

\section{Passo 1}

Buscamos a associação entre MCE e professor(es), particularmente, estudos que façam referência à prática pedagógica ou ao desenvolvimento profissional docente.

\begin{tabular}{|c|c|}
\hline AUTOR(ES)/ANO & TÓPICOS IMPORTANTES \\
\hline Aguiar e Oliveira, 2014 & $\begin{array}{c}\text { Apreendem que a relação dos professores com os MCE pode ser observada como ocorre a apropriação, } \\
\text { a seleção, a transformaçáo o posicionamento perante o contexto escolar. No artigo, procuraram } \\
\text { compreender como os professores lidam com a recontextualizaçáo dos textos dos Materiais Curriculares } \\
\text { Educativos na prática pedagógica. }\end{array}$ \\
\hline Aguiar e Oliveira, 2017 & $\begin{array}{r}\text { As cinco concepçôes sobre o uso dos MCE são: Seguindo o texto; Baseando no texto; Interpretando o } \\
\text { texto; Colaborando com o texto; Recontextualizando o texto. }\end{array}$ \\
\hline Bairral, 2016 & CUtiliza o "valor atribuído" e o "metacognitivo", que são âmbitos dos aspectos do conhecimento \\
profissional para clarear as reflexóes docentes.
\end{tabular}




\begin{tabular}{|c|c|}
\hline Boas e Barbosa, 2016a & $\begin{array}{l}\text { O MCE produzido por uma comunidade social terá suas experiências imortalizadas por meio de recursos } \\
\text { como fotos, vídeos e narrativas. Por intermédio destes recursos, outra comunidade poderá usar este MCE } \\
\text { com as devidas adequaçóes conforme as suas práticas sociais. }\end{array}$ \\
\hline Boas e Barbosa, 2016b & $\begin{array}{c}\text { Consideram que a aprendizagem docente se refere a mudanças de participação do professor na prática } \\
\text { pedagógica escolar e de outras práticas, como ambiente familiar ou de formação, que pode interferir no seu } \\
\text { saber fazer docente. Logo, os MCE podem provocar mudanças na participação dos docentes nas práticas } \\
\text { pedagógicas escolares. }\end{array}$ \\
\hline Oliveira, 2016 & $\begin{array}{c}\text { O MCE visa apoiar o saber-fazer dos professores. O MCE produzido pelo Programa Observatório da } \\
\text { Educação (OBEDUC) apresenta práticas pedagógicas desenvolvidas pelos membros dos grupos dos } \\
\text { projetos OBEDUC, sendo uma forma de comunicaçáo, por intermédio de narrativas escritas e orais da } \\
\text { realização de atividades de Matemática em sala de aula, possibilitando aos graduandos de licenciatura } \\
\text { e outros professores uma prévia das práticas pedagógicas escolares, potencializando o desenvolvimento } \\
\text { profissional docente. }\end{array}$ \\
\hline Oliveira e Barbosa, 2016 & $\begin{array}{l}\text { O MCE como um potencial material para apresentar a prática de ensino dos contextos escolares para uma } \\
\text { formaçáo inicial de professores. }\end{array}$ \\
\hline Palanch, 2016 & $\begin{array}{c}\text { Os professores são as peças principais nas transformaçóes das concepções curriculares cujos resultados são } \\
\text { materializados em planos de aulas e orientaçôes pedagógicas, daí a necessidade de compreender a relação } \\
\text { dos professores com os MCE. }\end{array}$ \\
\hline $\begin{array}{l}\text { Prado, Oliveira e } \\
\text { Barbosa, } 2014\end{array}$ & Mencionam que MCE trazem meios de apresentar o conteúdo que pode ser e como pode ser ensinado. \\
\hline $\begin{array}{l}\text { Prado, Oliveira e } \\
\text { Barbosa, } 2016\end{array}$ & $\begin{array}{l}\text { Os MCE são elaborados com intenção de contribuir com as práticas pedagógicas inovadoras no contexto } \\
\text { escolar. Além disso, os MCE mostram como os conteúdos matemáticos podem ser ensinados e indicar } \\
\text { como organizar o ambiente para aprendizagem. }\end{array}$ \\
\hline $\begin{array}{l}\text { Silva, Barbosa e Oliveira, } \\
\qquad 2012\end{array}$ & $\begin{array}{l}\text { Distintos professores podem utilizar os MCE de maneiras diferentes, resultantes de distintos discursos } \\
\text { pedagógicos exercidos em divergentes contextos pedagógicos. }\end{array}$ \\
\hline
\end{tabular}

Quadro 4 - Organização dos trabalhos selecionados

Fonte: Elaboração própria

Dos 11 artigos explicitados no Quadro 4, a formação continuada dos professores é evidenciada em 10 artigos, enquanto em apenas um artigo (OLIVEIRA; BARBOSA, 2016) há referência à formação inicial.

Aguiar e Oliveira (2014) destacam que os MCE podem ser apontados como mediadores entre o currículo planejado e a prática pedagógica (STEIN; KIM, 2009), por conterem conteúdos, estratégias e possibilidades de uso nas aulas. Aguiar e Oliveira (2017) argumentam que, no final da década de 1990, nos Estados Unidos, surgiram opinióes negativas sobre a produção e o uso do livro didático. Foram inúmeras discussóes e os autores começaram a elaborar MCE como apoio ao aprendizado docente.
Bairral (2016) relata que há inúmeros objetos educacionais disponíveis na internet, mas nenhum garante um processo de aprendizagem e de interação com o objeto. $\mathrm{O}$ autor comenta que existem diversos portais educacionais, porém o conteúdo deles não propicia a aprendizagem docente a partir das situaçóes ilustradas. Um contraexemplo citado pelo autor são os materiais multimídia elaborados pela Universidade Estadual de Londrina (PR), que contêm recortes de vídeo em diferentes momentos das aulas, atividades escritas pelos alunos, narrativas dos professores e planos de aulas.

Boas e Barbosa (2016a) comentam que o recurso pedagógico poderá constar nos materiais didáticos por intermédio de links de grupos de discussões que 
apresentam planejamento de aulas, vídeos e relatos de docentes ao aplicar atividades e comentários das soluçóes realizadas por alguns alunos. $\mathrm{Na}$ mesma direção, Boas e Barbosa (2016b) salientam que, ao englobar componentes educativos, um MCE possibilita aos docentes a noção prévia do saber-fazer apoiando o seu exercício profissional (DAVIS; KRAJCIK, 2005).

Boas e Barbosa (2016b) comentam que os recursos contidos no MCE provocaram mudança no tratamento das atividades (LLOYD, 2009), pois uma educadora passou a buscar o raciocínio contido nos algoritmos, auxiliando-a no seu fazer docente e, assim, transformou a sua prática em sala de aula. Boas e Barbosa (2016b) contam também que o MCE usado por um grupo de professores na pesquisa de Choppin (2011) provocou modificações ao ministrar suas aulas, passando a usar estratégias investigativas por intermédio de questionamentos e orientaçóes com os alunos. Essas pesquisas demonstraram que os MCE proporcionaram uma participação diferenciada em aula com novas propostas pedagógicas e acarretaram a aprendizagem docente.

Em Oliveira (2016), o desenvolvimento profissional de professores é visto como um processo constante de transformação e de formação do indivíduo, principalmente, em uma comunidade profissional. Essa comunidade pode ser um grupo colaborativo constituído de participantes voluntários na busca de um objetivo comum, o crescimento profissional. Os MCE têm a proposta de apoiar os professores no desenvolvimento e nas mudanças das práticas pedagógicas e, sendo disponibilizados online, poderão ter uma abrangência maior.

Oliveira e Barbosa (2016) referenciam os MCE como um tipo de material que possibilitará aos licenciandos em Matemática uma aproximação de propostas pedagógicas a partir de detalhes de experiências de professores no ensino de certo conteúdo e oportunizando meios de levantar discussóes sobre a prática.
Palanch (2016) menciona Stein e Kim (2009) quando dizem que os pontos cruciais dos MCE são a apresentação prévia do comportamento dos estudantes (pensar e fazer) perante as atividades e a clareza do material por estabelecer uma comunicação direta com o professor ao expor as ideias pedagógicas e o conteúdo matemático das tarefas. A compreensão da relação do professor com um MCE, particularmente, a análise e a forma como o educador adapta, adota ou improvisa tal material em suas aulas é sublinhada por Brown (2009).

Prado, Oliveira e Barbosa (2014) apontam que os habituais guias de professores contêm uma base de estratégias de ensino, mas não constituem um suporte para auxiliá-los na apropriação dessas estratégias. Um MCE também deve ajudar os docentes a interpretar e a compreender ideias e dúvidas dos discentes. Prado, Oliveira e Barbosa (2016) enfatizam que os MCE, ao trazerem narrativas ou vídeos com aspectos de algum conteúdo decorrentes de alguma aula, oferecem ao professor alternativas para organizar, abordar e desenvolver tarefas a partir do momento em que ele observa as ideias dos alunos ao realizar outra tarefa. Nesse caso, o educador pode decidir, por exemplo, se é viável realizar a tarefa individual ou coletivamente.

Silva, Barbosa e Oliveira (2012) ressaltam que os MCE apresentam componentes de apoio ao professor, viabilizando a ele observar como se pode proceder com certa atividade no contexto escolar. Assim, os MCE podem ter um papel primordial no cotidiano escolar do professor, pois esses materiais caracterizam dimensóes do que e do como ensinar. Por conseguinte, os professores podem usar os MCE para nortear seus planejamentos e suas aulas. Os autores mencionam também que professores veteranos e novatos podem manusear os MCE de formas distintas. Além do mais, circunstâncias educacionais diferenciadas influenciam diferentes discursos pedagógicos. A forma como os professores utilizam os MCE depende de suas consideraçóes sobre 
o contexto escolar e sobre os processos de ensino e de aprendizagem.
No próximo passo, destacamos as pesquisas cujo interesse está na utilização do MCE pelo(s) professor(es).

\section{Passo 2}

O Quadro 5 ilustra os seis artigos capturados que abordam a utilização (ou análise) de MC ou MCE por docente(s).

\begin{tabular}{|c|c|}
\hline AUTOR(ES)/ANO & CARACTERIZAÇÃO \\
\hline Aguiar e Oliveira, 2014 & $\begin{array}{c}\text { O contexto do estudo refere-se às aulas de duas professoras de Matemática ao implementar tarefas presentes } \\
\text { nos Materiais Curriculares Educativos encontrados no ambiente virtual denominado Colaboraçáo ONLINE } \\
\text { em Modelagem Matemática. }\end{array}$ \\
\hline Bairral, 2016 & $\begin{array}{l}\text { Os dados analisados foram coletados em uma sessão presencial de pesquisa na qual cada participante, } \\
\text { professores em exercício e licenciandos, tiveram a oportunidade de acessar e navegar cada MCE do } \\
\text { site GEPETICEM. }\end{array}$ \\
\hline Boas e Barbosa, 2016a & $\begin{array}{l}\text { As colaboradoras da pesquisa foram duas professoras de escolas públicas de Salvador, na Bahia, que } \\
\text { utilizaram o MCE intitulado "Relaçốes métricas no triângulo retângulo" em suas turmas. }\end{array}$ \\
\hline Boas e Barbosa, 2016b & $\begin{array}{l}\text { As colaboradoras da pesquisa foram duas professoras de escolas públicas de Salvador, na Bahia, que } \\
\text { utilizaram o MCE intitulado "Relaçôes métricas no triângulo retângulo" em suas turmas. }\end{array}$ \\
\hline Palanch, 2016 & $\begin{array}{l}\text { Narrativa indireta de alguns professores participantes do segundo relatório institucional referente ao } \\
\text { projeto intitulado "Avaliação de Professores do Ensino Fundamental da Secretaria Municipal de Educação } \\
\text { de São Paulo em relação a documentos e materiais de apoio à organização curricular na área de Educação } \\
\text { Matemática", que demonstra a relação dos professores com os MC e MCE. }\end{array}$ \\
\hline $\begin{array}{l}\text { Silva, Barbosa e } \\
\text { Oliveira, } 2012\end{array}$ & $\begin{array}{c}\text { Analisaram as aulas de um professor iniciante ao usar MCE do ambiente virtual Colaboraçâa ONLINE em } \\
\text { Modelagem Matemática. }\end{array}$ \\
\hline
\end{tabular}

Quadro 5 - Organização dos trabalhos selecionados

Fonte: Elaboração própria

Aguiar e Oliveira (2014) acompanharam duas professoras que utilizaram os MCE diferentes do ambiente Colaboração ONLINE em Modelagem Matemática ${ }^{6}$. Os autores apresentaram as seguintes categorias: alteração do planejamento contido no Material Curricular Educativo e transformação da natureza das questóes propostas nele. Perceberam que, quando os docentes utilizam os MCE, eles fazem adaptaçóes nos textos na intenção de atender a diferentes possibilidades e concepções existentes na prática pedagógica. Observaram também que, no momento em que os educadores se apoderam do MCE, eles escolhem e evidenciam uma seleção de textos e de outros elementos que guiam as concepções existentes e permanentes em sua prática pedagógica.
Bairral (2016) relatou uma análise a partir de uma sessão de três horas com setes professores da Educação Básica e um licenciando em que acessaram e navegaram em MCEO disponíveis no portal do Grupo de Estudos e Pesquisas das Tecnologias da Informação e Comunicação (TIC) em Educação Matemática (GEPETICEM) ${ }^{7}$. O autor buscou identificar melhorias no aprendizado de professores e, para isso, aplicou um roteiro de perguntas e verificou os diários de campo dos pesquisadores. Baseado em Brown (2009), observou a interpretação de cada professor para o MCEO a fim de obter informaçôes para o aprendizado dos participantes. Os valores atribuídos pelos professores a partir das informações contidas no material possibilitaram uma 
clareza sobre o conceito de polígono. A análise estimulou o grupo a realizar estudos vindouros para investigar que reflexões de cunho metacognitivo afloram apenas quando os docentes avaliam ou adaptam o material para o uso em aula, que será viável, segundo Bairral (2016), diante de uma análise de educadores implementando os materiais.

Boas e Barbosa (2016a) analisaram como duas professoras utilizaram em suas turmas o MCE intitulado "Relaçôes métricas no triângulo retângulo", disponível no ambiente virtual do Observatório da Educação Matemática $(\mathrm{OEM} / \mathrm{BA})^{8}$. Os autores identificaram formas distintas de participação de cada professora na aula de Matemática ao utilizar MCE, a saber: participar seguindo as sugestóes e os exemplos do material, diversificar as estratégias de ensino e usar o material como acessório na sala de aula.

A pesquisa de Boas e Barbosa (2016b) observou oportunidades de aprendizagens identificadas por professores de Matemática ao utilizarem MCE do OEM/ BA. Os autores caracterizaram três oportunidades de aprendizagens docentes, analisadas nas entrevistas, que estão relacionadas: à abordagem comunicativa, ou seja, aos diferentes modos de interação entre professor e alunos; aos cenários para investigação, que auxiliam um trabalho de exploração e investigação; e ao desenvolvimento profissional. $\mathrm{Na}$ abordagem comunicativa, perceberam que utilizar os materiais oportuniza opçóes ao discurso do professor. As oportunidades de aprendizagens aos cenários para investigação estão vinculadas à abordagem comunicativa dialógica, pois viabilizam a vivência em diversos ambientes de aprendizagem na sala de aula e validam o conteúdo matemático após a dedução e o debate coletivo. Essas duas oportunidades de aprendizagem são possíveis junto à viabilidade de presenciar uma orientação de $\Omega$ profissional, mas que assegura a semelhança a experiências de outros professores com tarefas exploratórias. Os autores indicam que investigaçóes futuras, que acompanhem professores ao manusearem os MCE, possam sinalizar que oportunidades de aprendizagens podem estabelecer aprendizagens docentes.

A pesquisa de Palanch (2016) foi realizada com um grupo voluntário de professores de Matemática que atuam no Ensino Fundamental da Secretaria Municipal de Educação de São Paulo e usam o Caderno de Apoio e Aprendizagem de Matemática (CAA - Matemática) em suas turmas. $\mathrm{O}$ estudo evidenciou que, nos espaços escolares, há reflexões sobre as práticas pedagógicas, mas pouca análise de Orientaçóes Curriculares como materiais formativos, como é o caso de um CAA. Também foi mencionado pelos participantes que a formação continuada é essencial para refletir junto com os profissionais da área educacional sobre os processos de ensino e de aprendizagem e, assim, viabiliza a qualificação de procedimentos didáticos.

Silva, Barbosa e Oliveira (2012) relatam os procedimentos de um professor estreante em suas aulas ao executar as atividades de um MCE sobre Modelagem Matemática do ambiente Colaboração ONLINE em Modelagem Matemática (COMMa). Este educador prosseguiu com as atividades com os alunos, conforme a prescrição do MCE, mas com alguns procedimentos diferentes do que constava no material. Iniciou a aula usando um vídeo que náo fazia parte do MCE para ambientar os alunos ao tema escolhido. Esse vídeo trazia informaçóes que constavam no MCE. Em seguida, na realização das atividades, o professor organizou a turma em grupos e orientou os estudantes para a realizaçáo das tarefas. Demarcou cada etapa das atividades com questionamentos aos alunos para acompanhar as suas resoluções, além de acrescentar perguntas extras ao material. A pesquisa mostra que os professores iniciantes recontextualizam os MCE de Modelagem Matemática perante um sequenciamento didático que se sintoniza aos princípios da sua prática pedagógica. 


\section{CONSIDERAÇÓES FINAIS}

Os 18 artigos mapeados e sintetizados neste artigo ilustram que pesquisas nacionais centradas no uso de MCE na formação continuada de professores ainda é incipiente. Dos 18 artigos, detectamos que sete evidenciam MC, oito referem-se a MCE e três mencionam ambos os construtos. A partir dessa organização, estamos trabalhando no sentido de melhor esclarecer a conceituação de Material Curricular Educativo como um tipo de recurso que promove o aprendizado do professor. Particularmente, buscaremos situar que aprendizado docente os estudos mostram quando um MCE entra em cena. Pesquisas como as de Boas e Barbosa (2016a, 2016b) indicam que aprender com um MCE implica oportunizar ao docente formas distintas de participação em contextos com reflexão profissional colaborativa.

Os estudos mapeados também nos indicam pontos cruciais dos MCE para os professores, particularmente, como se pode estabelecer a relaçáo entre os educadores e o uso desses materiais em sua prática pedagógica. A preocupação com a aprendizagem docente e a discente, a ilustração de práticas reais (e não hipotéticas) de aprendizagens ou respostas instigantes que efetivamente aconteceram em uma sala de aula são aspectos a serem considerados em um MCE. As situações sugeridas em um MCE não são meras receitas a serem reproduzidas. Elas precisam ser reinterpretadas, apropriadas e (re)significadas na própria prática do docente que a analisa (BROWN, 2009). Um MCE também precisa conter informaçóes reflexivas de quem o utiliza (BAIRRAL, 2016).

Finalmente, esperamos que este artigo sirva aos jovens pesquisadores como fonte de inspiração para a realização de mapeamentos de investigaçóes em Educação Matemática e que, a partir dele, oriente a construção da sua problemática de pesquisa e auxilie na produção de novos conhecimentos para o problema de pesquisa proposto.

\section{A MAPPING OF RESEARCHES ON THE USE OF EDUCATIONAL CURRICULAR MATERIALS IN MATHEMATICS TEACHER TRAINING}

\section{Abstract}

This article presents a literature review of studies based on the use of Educational Curricular Materials (ECM) in professional development of mathematics teachers. The ECMs are resources prepared to support teachers, particularly because they contain information that allow them to have a notion of how to plan the classes or the new pedagogical practices. In this survey 18 articles were captured in nine mathematical education journals. It was possible to verify a deficit of ECM research in the Brazilian studies of mathematics education with teachers. This paper brings contributions to the conceptualization of this type of resource and illustrates how the researches are using such formative materials.

Keywords: Mathematics Education. Educational curriculum materials. Professional teacher development. Continual Mathematics formation. Obligatory education.

UNA CARTOGRAFÍA SOBRE EL USO DE MATERIALES CURRICULARES EDUCATIVOS EN LA FORMACIÓN CONTINUA DE DOCENTES

\section{Resumen}

El presente artículo presenta un levantamiento bibliográfico deinvestigaciones pautadas en el usode Materiales Curriculares Educativos (MCE) como propuesta de desarrollo profesional de profesores 
de matemáticas. MCE son materiales preparados para apoyar a los profesores, por contener recursos que les posibilitan una noción previa de cómo estructurar las clases de matemáticas y la forma de interacción con los estudiantes en el desarrollo de prácticas pedagógicas. En este levantamiento se detectaron 18 artículos en nueve periódicos de educación matemática, siendo posible verificar un déficit de estudios brasileños sobre el uso de MCE por profesores de la Educación Básica. El artículo presenta contribuciones respecto a la conceptualización de ese tipo de recurso e ilustra como las investigaciones están utilizando esos materiales formativos.

Palabras clave: Educación Matemática. Materiales curriculares educativos. Desarrollo profesional docente. Formación continuada en Matemáticas. Educación básica.

\section{Notas}

Este artigo é uma versão revisada e ampliada de Arquieres e Bairral (2018).

Disponível em: <http://cursos.ufrrj.br/posgraduacao/ ppgeducimat/>. Acesso em: 28 maio 2018.

Esse tipo de levantamento "faz referência à identificação, à localização e à descrição das pesquisas realizadas em um determinado tempo, espaço e campo de conhecimento" (FIORENTINI; PASSOS; LIMA, 2016, p. 18). Neste artigo, as expressōes mapeamento de pesquisa e levantamento bibliográfico serão utilizadas como sinônimos.

Neste primeiro momento, optamos por olhar apenas os periódicos por considerarmos que, nesses veículos, os textos costumam apresentar maior densidade teórica e detalhamento metodológico, e por trazerem resultados em caráter mais conclusivo. Artigos publicados em Anais de congressos (ENEM, SIPEM etc.) podem ser fontes para outras análises.

A captura se iniciou em 2011 porque é nesse período que começam a surgir pesquisas divulgadas, pioneiramente no Brasil, por Jonei Barbosa e Andreia Oliveira (UFBA). Além do mais, internacionalmente, uma obra de referência para os MCE é a de Remillard et al. (2009).

Disponível em: <http://www.colaboracaoprofessores.blogspot. com.br/> Acesso em: 20 maio 2018 .

http://www.gepeticem.ufrrj.br/portal/categoria/materiaiscurriculares/ Acesso em: 30 junho 2018.

Disponível em: http://www.educacaomatematica.ufba.br/tarefa. php?cod=13 Acesso em: 10 maio 2018.

\section{REFERÊNCIAS}

AGUIAR, W. R. A transformaçāo de textos de materiais curriculares educativos por professores de matemática nas práticas pedagógicas: uma abordagem sociológica com a lente teórica de Basil Bernstein. 2014. 111f. Dissertação (Mestrado em Ensino, Filosofia e História das Ciências) - Universidade Federal da Bahia, Feira de Santana, 2014.

AGUIAR, W. R.; OLIVEIRA, A. M. P. A transformação dos textos dos materiais curriculares educativos por professores de Matemática: uma análise dos princípios presentes na prática pedagógica. BOLEMA, v. 28, n. 49, p.580-600, 2014.

AGUIAR, W. R.; OLIVEIRA, A. M. P. Uma análise sociológica Bernsteiniana sobre os usos de materiais curriculares educativos. Educação Matemática Pesquisa, v.19, n.1, p. 403-422, 2017.

ARQUIERES, D. D.; BAIRRAL, M. A. Um mapeamento inicial sobre o uso de materiais curriculares educativos na formação continuada de docente.in: Encontro de Educação Matemática do Estado do Rio de Janeiro, 7, 2018, Rio de Janeiro. Anais, Rio de Janeiro, 2018.

BAIRRAL, M. A. Materiais curriculares educativos online como uma estratégia ao desenvolvimento profissional em Matemática. Zetetiké, v.24, n.1, p.75-92, 2016.

BOAS, J. V.; BARBOSA, J. C. Formas de Participação do Professor de Matemática ao Utilizar Materiais Curriculares Educativos em Sala de Aula. JIEEM, v.9, n.2, p. 143-166, 2016a.

BOAS, J. V.; BARBOSA, J.C. Oportunidades de aprendizagens docentes ao utilizar materiais curriculares educativo. Boletim Gepem, n.69, p.91-104, 2016b.

BROWN, M. W. The Teacher-Tool relationship: theorizing the design and use of curriculum materials. In: J. T. Remillard, B. A. Herbel-Eisenmann, \& G. M. Lloyd (Eds.), Mathematics teachers at work: connecting curriculum maerials and classroom instruction). p.17-36. New York: Routledge, 2009.

CRISOSTOMO, E.; JANUÁRIO, G.; LIMA, K. Relação professor-materiais curriculares em Educação Matemática: análise de alguns resultados de pesquisas. Educação Matemática em Revista, n. 53, p.62-74, 2017. 
DAVIS, E. A.; KRAJCIK, J. S. Designing Educative Curriculum Materials to Promote Teacher Learning. Educational Researcher, Washington, v. 34, n. 3, p. 3-14, abr. 2005.

EISENMANN, T.; EVEN, R. Similarities and differences in the types of algebraic activities in two classes taught by the same teacher. In: REMILLARD, J. T.; HERBEL-EISENMANN, B. A.; LLOYD, G. M. (Ed.). Mathematics Teachers at Work: connecting curriculum materials and classroom instruction. 1. ed. New York: Routledge, 2009. p. 152-170.

FIORENTINI, D.; PASSOS, C. L. B.; LIMA, R. C. R. (Org.). Mapeamento da pesquisa acadêmica brasileira sobre o professor que ensina matemática: período 2001-2012. Campinas, SP: FE/UNICAMP, 2016. P.17-42. ISBN 978-85-7713-1983. Disponível em: <https://www.fe.unicamp.br/pf-fe/ pagina_basica/58/e-book-mapeamento-pesquisa-pem.pdf.>. Acesso em: 26 mai. 2018.

JANUARIO, G.; LIMA, K.; MANRIQUE, A. L. A Relação professor-materiais curriculares como temática de pesquisa em educação matemática. Educação Matemática Pesquisa, v.19, n.3, p. 414-434, 2017.

LIMA, E. T.; BORBA, R. E. S. R. Relaçôes entre o raciocínio combinatório e o probabilístico: como estão propostas em currículos prescritos? Perspectivas da Educação Matemática, v.10, n. 24, p. 816-833, 2017.

OLIVEIRA, A. M . P. Desenvolvimento profissional de professores que ensinam Matemática: colaboração e materiais curriculares (educativos). Zetetiké, v.24, n.1, p. 157-171, 2016.

OliveirA, A. M. P. de; BARBOSA, J. C. A Produção de Materiais Curriculares Educativos em Grupos Colaborativos. In M. A. Gonçalves Júnior, E. M. Cristóvão, \& R. C. R. Lima (Orgs.). Grupos colaborativos e de aprendizagem do professor que ensina Matemática: repensar a formação de professores é preciso! Campinas, SP: FE/UNICAMP, 2014. p.118-126.

OLIVEIRA, A. M. P. de; BARBOSA, J. C. Potencialidades de materiais curriculares educativos para a componente curricular prática de ensino. Educação Matemática em Revista, n.49B, p.116-123, 2016

OliveIRA, W. C.; OLIVEIRA, A. M. P. de; SILVA, L.A. da. Análise de materiais curriculares elaborados por professores na perspectiva dos marcadores de tarefas. Educação Matemática Pesquisa, v.19, n.3, p.42-66, 2017.

OLIVEIRA, B.; RIBEIRO, A.; POWELL, A. O Conceito de simetria e o ensino de Álgebra: analisando materiais curriculares da Educação Básica. GEPEM, n. 69,p. 105-117, 2016.

PALANCH, W. B. L. Professores que ensinam Matemática e suas relaçóes com materiais curriculares e materiais curriculares educativos. Perspectivas da Educação Matemática, v.9, n.21, p. 1058-1074, 2016.

PACHECO, D. R.; PIRES, C.M.C. Impactos de materiais curriculares na prática do professor que ensina Matemática nos anos iniciais. REVEMAT, v.10, n.2., p.227-242, 2015.

PIRES, C. M. C. Investigaçóes e vivências sobre a utilização de materiais curriculares por professores de Matemática. Educação Matemática em Revista, n. 48, p. 47-63, 2016.

PRADO, A. S. P.; OLIVEIRA, A. M. P.; BARBOSA, J. C. Uma análise sobre a imagem da dimensão interacional da prática pedagógica representada em materiais curriculares Educativos. Educação Matemática Pesquisa, v.16, n.2, p.505535, 2014.

PRADO, A. S. P.; OLIVEIRA, A. M. P.; BARBOSA, J. C. Uma análise sobre a imagem da dimensão estrutural da prática pedagógica em Materiais Curriculares Educativos. Bolema, v. 30, n. 55, p.738-762, 2016.

REMILLARD, J. T.; HERBEL-EISENMANN, B. A.; LLOYD, G. M. (Eds.). Mathematics teachers at work: connecting curriculum materials and classroom instruction. New York: Routledge, 2009.

Silva, M. S. d.; Barbosa, J. C.; Oliveira, A. M. P. d. O sequenciamento do ambiente de modelagem matemática a partir do contato com materiais curriculares Educativos. Acta Scientiae, v.14, n.2, p.240-259, 2012.

Enviado em 30 de maio de 2018. Aprovado em 10 de julho de 2018. 